\title{
Vertical distribution of early developmental stages in two coexisting clupeoid species, Sardinella aurita and Engraulis encrasicolus
}

\author{
Ana Sabatés*, Nuria Zaragoza, Claudia Grau, Jordi Salat \\ Institut de Ciències del Mar, CSIC, Passeig Marítim 37-49, 08003 Barcelona, Spain
}

\begin{abstract}
In recent years a northward expansion of Sardinella aurita has been reported in the western Mediterranean. Considering the coexistence of its larvae with those of the dominant species Engraulis encrasicolus, the present study was conducted to compare their vertical distributions in 2 areas off the Catalan coast with different vertical environmental conditions. During summer, the water column was stratified with a deep chlorophyll maximum (DCM) beneath the pycnocline. However, the southern area, under the influence of the Ebro River, was characterized by a secondary surface chlorophyll maximum. Vertical distribution of larval food, nauplii and copepodites showed good agreement with the high chlorophyll layers. In the earliest stages of development, larvae of both species remained in the upper levels. From $6 \mathrm{~mm}$ standard length on they developed a day/night migratory behaviour to search for food during the day (feeding period). Therefore, in the south, where the abundance of potential food in the upper layers was relatively high, larvae of both species remained in the upper levels during the day. However, in the north, where food was restricted to the DCM, only E. encrasicolus larvae were able to reach these deep levels. The low temperatures $\left(\sim 15^{\circ} \mathrm{C}\right)$ detected at the DCM may restrict the vertical migration of $S$. aurita in accordance with their thermophilic character. This limitation might represent a restriction for the northward expansion of this species in the western Mediterranean.
\end{abstract}

KEY WORDS: Sardinella aurita - Engraulis encrasicolus · Larvae · Eggs · Microzooplankton · Vertical distribution $\cdot$ NW Mediterranean

\section{INTRODUCTION}

During recent decades, a warming trend in Mediterranean waters has been reported, both at the surface as well as in deep waters (Rohling \& Bryden 1992, Bethoux \& Gentili 1996, Salat \& Pascual 2002). In relation to this tendency, fish species characteristic of the warm waters of the southernmost parts are extending their distribution range, since they are appearing more frequently in the northernmost and colder areas (Francour et al. 1994, Astraldi et al. 1995, Bianchi \& Morri 2000). In the NW Mediterranean, the most abundant species of small pelagic fish are the European anchovy Engraulis encrasicolus and the sardine Sardina pilchardus (Lleonart \& Maynou 2003). Another pelagic species, the round sardinella Sardinella aurita, is a thermophilic species, found frequently in the warmer waters of the southern Mediterranean (Ben Tuvia 1960). Nevertheless, in the past few years, a gradual northward expansion and an increasing abundance of $S$. aurita in the northern sector has been documented in connection with the warming of the sea in the area (Sabatés et al. 2006).

In the NW Mediterranean, the reproductive period of the 2 dominant species, sardine and anchovy, takes place in completely opposite periods of the year: autumn/winter and spring/summer, respectively. The reproduction of round sardinella occurs in summer, from the end of June to September, when the surface temperature reaches the highest annual values (Oliver 
\& Navarro 1952, Palomera \& Sabatés 1990, Somarakis et al. 2002). Therefore, the spawning periods of the anchovy and round sardinella coincide during the summer months. Since both species dwell on the continental shelf, their larvae coexist in the plankton during this period of the year.

The summer period in the NW Mediterranean is characterised by a stratified water column, with a marked thermocline (and pycnocline). Consequently, vertical water movement is very limited, and almost all the surface nutrients are depleted. Primary production remains limited to a deep chlorophyll maximum (DCM), a thin layer at the deepest levels of the photic zone (Estrada 1985), where there is a compromise between nutrient concentration and light intensity (Estrada et al. 1993). The only nutrient contribution to the surface during the fully stratified season comes from riverine runoff water (Blanc et al. 1969). Although the contribution of this source to the total primary productivity is only between 10 and $20 \%$ (Salat et al. 2002), it is relevant because it is able to maintain surface planktonic production in areas under the influence of the river discharges in summer.

In such variable vertical conditions of temperature, density, light and food concentration, it is relevant to determine where the larvae of Sardinella aurita and Engraulis encrasicolus are located in the water column. In particular, what are the vertical distribution patterns, including the possible day/night variations in relation to the environmental variables? Fish larvae, like many other planktonic organisms, perform diel vertical migrations (Neilson \& Perry 1990). Most of them are visual predators that typically cease feeding at night, when light levels fall below the minimum required for successful foraging (Blaxter 1986, Sabatés et al. 2003). Therefore, the position of larvae in the water column will indicate the availability of prey they encounter during the feeding periods, and the foraging environment available to larval fishes will influence their growth and survival.

In the Mediterranean, studies on the vertical distribution of anchovy eggs and larvae reported that the eggs are found largely in the upper $10 \mathrm{~m}$ of the water column (Olivar et al. 2001, Coombs et al. 2003). In the case of larvae, some authors indicated that they are found mainly in the surface layers (Olivar \& Sabatés 1997, Coombs et al. 2003) during both the day and night, whereas others describe nictemeral migrations in advanced larval developmental stages in relation to the concentration of food, with larvae being found deeper during the day than during the night (Palomera 1991, Olivar et al. 2001). However, there are no studies concerning the vertical distribution patterns of Sardinella aurita, either in the Mediterranean or in other geographical areas.
Considering the recent northward expansion of Sardinella aurita into the western Mediterranean and the coexistence of its larvae with those of the dominant species Engraulis encrasicolus, the present study was conducted to describe the vertical distribution of early developmental stages of both species in 2 areas off the Catalan coast with different environmental conditions. Specific aims were (1) to compare ontogenetic and diel differences in their vertical distributions in relation to the physical structure and distribution of microzooplankton in the water column, and (2) to determine weather the vertical migration behaviour of $S$. aurita could represent a difficulty to the expansion of this species towards the north.

\section{MATERIALS AND METHODS}

The Catalan coast (NW Mediterranean) is characterised by a continental shelf, which is, in general, quite narrow. It only widens clearly in the southernmost part, in the vicinity of the delta of the Ebro River, and in the north between the main submarine canyons. The southern shelf of the Catalan coast receives a significant riverine inflow from the Ebro, which, under normal conditions, accounts for around $90 \%$ of the total fresh water discharges along the Catalan coast. The northern shelves are more exposed to the winds, which leads to a deeper surface mixed layer with generally lower surface temperatures during the summer. Likewise, the levels of surface chlorophyll are higher on the southern shelf than in the north because of the effect of the waters from the Ebro River.

Sampling was carried out during July 2003 and July 2004, coinciding with the spawning period of Sardinella aurita and Engraulis encrasicolus. Determination of the basic hydrographic parameters was performed with CTD casts at stations distributed along transects, from near the coast to the shelf edge, along the Catalan coast (NW Mediterranean). Stations on transects were placed 7.5 nautical miles apart, and the distance between transects was 10 nautical miles (Fig. 1). The CTD employed was a Neil Brown Mark III with an attached SeaTech fluorometer. Profiles of temperature, salinity, density and fluorescence were averaged at $1 \mathrm{~m}$ intervals. The depth of the pycnocline was established where the maximum of the vertical density gradient (obtained by centred differences at $1 \mathrm{~m}$ intervals) was observed.

To determine the vertical distribution of fish eggs and larvae, sampling was focused on 2 areas of the Catalan coast where the continental shelf was relatively wide: one in the southern part, which was called the 'southern area' and the other in the north that was denoted the 'northern area' (Fig. 1). Five stations were 


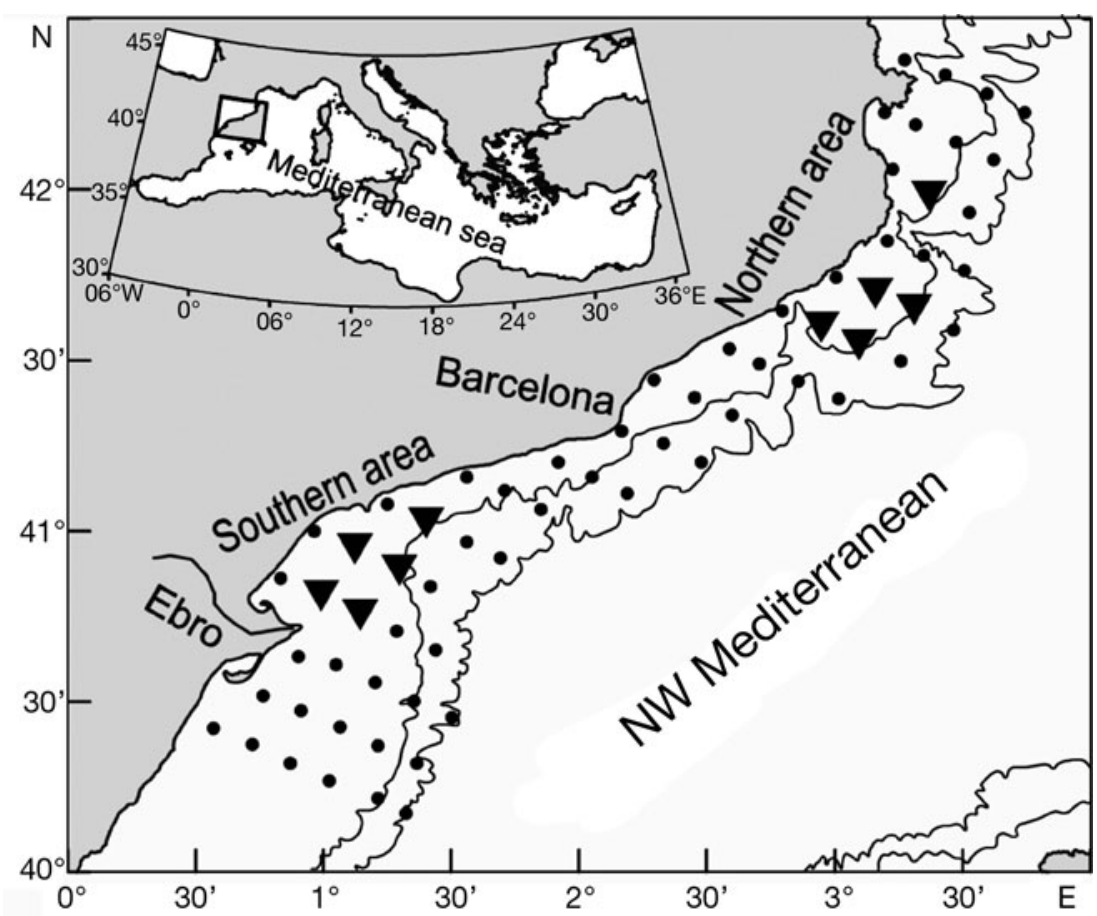

Fig. 1. Study site showing the sampling stations in the southern and northern areas. Circles: CTD casts; triangles: Longhurst-

Hardy Plankton Recorder (LHPR) tows.The isobaths shown are 200 and $1000 \mathrm{~m}$

sampled in each area (3 during the day and 2 during the night) during July 2003 and July 2004. Vertically stratified zooplankton samples for fish larvae $(45 \mathrm{~cm}$ mouth diameter, $333 \mu \mathrm{m}$ mesh) and microzooplankton (9 cm diameter, $53 \mu \mathrm{m}$ mesh) were collected simultaneously using a double Longhurst-Hardy Plankton Recorder net (LHPR; Williams et al. 1983). Tows were taken obliquely from the surface down to a maximum depth of $120 \mathrm{~m}$, with a sampling time of 4 min stratum ${ }^{-1}$ and a vertical resolution of $10 \mathrm{~m}$. Towing speed was 3.5 knots. The volume of water filtered by each net was recorded by a flow meter attached to the mouth of the net. The average volume of filtered water was $34 \mathrm{~m}^{3}$ (6 SD) for the coarse net and $0.35 \mathrm{~m}^{3}(0.08 \mathrm{SD})$ by the fine mesh. Zooplankton samples were preserved in $5 \%$ formaldehyde buffered with sodium tetraborate.

In the laboratory, eggs and larvae of Sardinella aurita and Engraulis encrasicolus were sorted and identified from the $333 \mu \mathrm{m}$ samples, and their numbers were standardised to number per $100 \mathrm{~m}^{3}$. The standard length (SL) of larvae was measured to the nearest $0.1 \mathrm{~mm}$. For the microzooplankton, aliquots were made from the $53 \mu \mathrm{m}$ samples for counting nauplii and the copepodite stages of copepods. Two aliquots were taken from each sample, and at least 300 individuals in each aliquot were counted. Mean concentration in the aliquots was expressed as the number of individuals per cubic metre.

The mean depth of eggs and larvae, $Z_{\mathrm{CM}}$, in each sample was calculated as the centre of mass of the larval distribution:

$$
Z_{\mathrm{CM}}=\sum_{i=1}^{n} P_{i} Z_{i}
$$

where $P_{i}$ is the proportion of larvae in the $i$ th depth stratum:

$$
P_{i}=\frac{C_{i} H_{i}}{\sum_{i=1}^{n} C_{i} H_{i}}
$$

$Z_{i}$ is the mean sampling depth of the ith depth stratum, $C_{i}$ is the concentration of larvae in the ith depth stratum and $H_{i}$ is the width of the ith depth stratum.

One-way ANOVA was used to assess the significance of differences in thermocline depth between the 2 areas, for each year. In addition, 3-way ANOVA was performed on $Z_{\mathrm{CM}}$ values for each species, by size, to determine the interaction between year (2003/2004), area (north/south) and time (day/night). Analyses were performed on $\log (x+1)$-transformed data. The Dunne test was conducted post hoc when significant differences were observed in interactions.

\section{RESULTS}

\section{Hydrography}

The horizontal temperature distributions in both years showed a marked surface front of nearly $2^{\circ} \mathrm{C}$, perpendicular to the coastline around $41^{\circ} 30^{\prime} \mathrm{N}$ (Fig. 2). However, surface temperatures were higher (between 

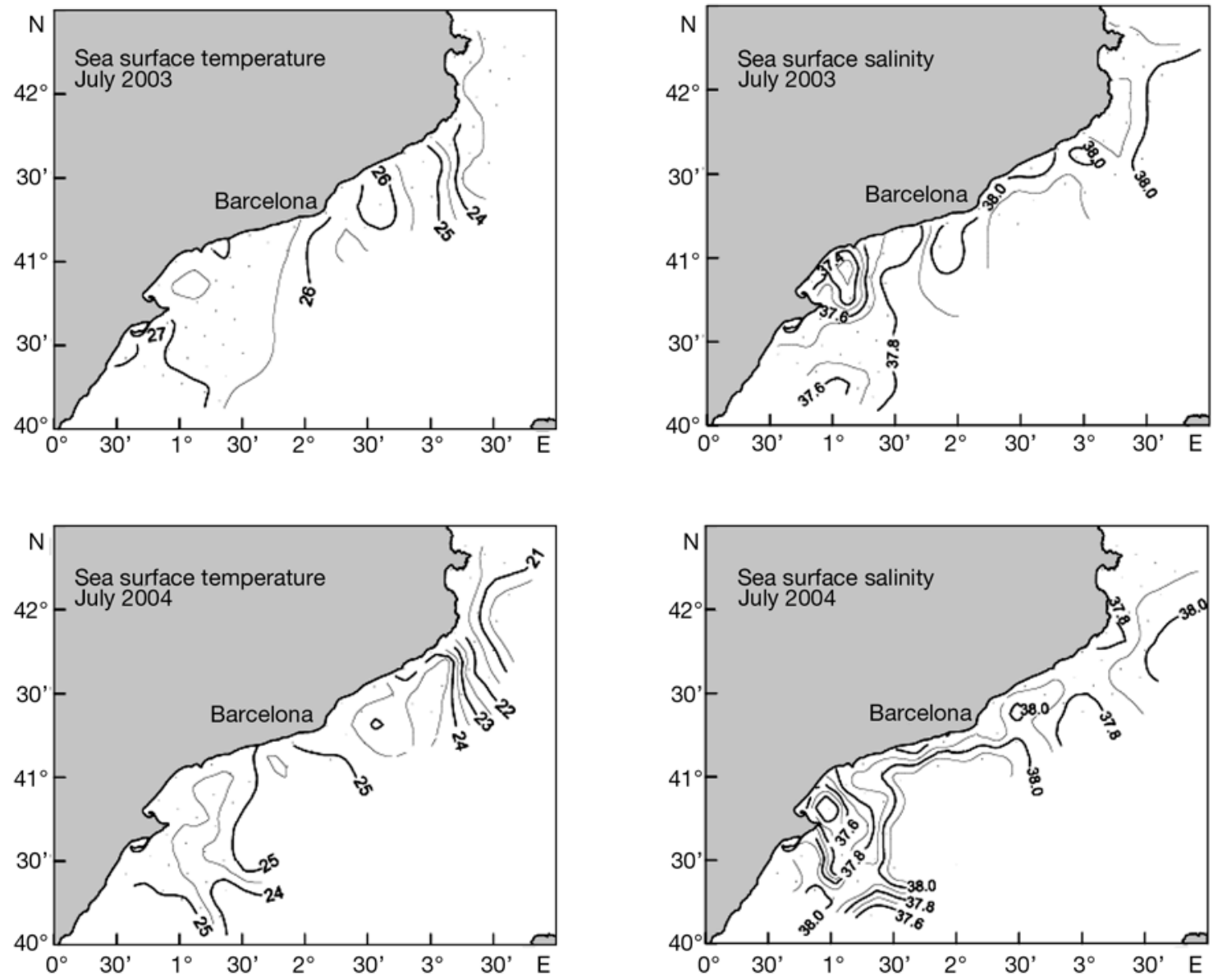

Fig. 2. Surface distribution of temperature (left-hand panels) and salinity (right-hand panels) for July 2003 (upper panels) and July 2004 (lower panels)

1 and $2^{\circ} \mathrm{C}$ ) in July 2003 than in July 2004. In fact, July 2003 was extremely hot. Surface salinity distributions showed uniform values (around 37.9) in the whole area sampled, except near the Ebro River, where values were lower ( 37.4 in 2003 and 37.7 in 2004) (Fig. 2). Relatively high surface chlorophyll patches were found during both cruises on the Ebro shelf, showing good correspondence with areas of low salinity, in association with the effect of riverine nutrient inputs.

The vertical structure of the water column was dominated by thermal stratification, which was typical of full summer (Figs. $3 \& 4$ ). In both years, the stations in the north area had a significantly $(p<0.03)$ deeper pycnocline (and thermocline) than those in the southern area (Table 1). Comparing the $2 \mathrm{yr}$, the thermoclines in 2003 were shallower than in 2004. The maximum density gradient was found in the southern area in 2003 (Table 1). Vertical fluorescence profiles were also typical of the season with a clear DCM located beneath the pycnocline. However, there was also a secondary surface chlorophyll maximum (SCM) in the southern area associated with the presence of low salinity surface waters from the Ebro River. Fluorescence values found at this SCM were close to those at the DCM in this southern area (Figs. $3 \& 4$ ).

\section{Microzooplankton}

Copepod nauplii and copepodites showed similar distribution patterns throughout the water column in the 2 studied years, although differences were observed

Table 1. Mean $( \pm \mathrm{SD})$ depth of the pycnocline and vertical density gradient at the pycnocline, by area and year

\begin{tabular}{|lllll|}
\hline & \multicolumn{2}{c}{$\begin{array}{c}\text { Depth of the pycnocline } \\
(\mathrm{m})\end{array}$} & \multicolumn{2}{c|}{$\begin{array}{c}\text { Vertical density gradient } \\
\left(\mathrm{kg} \mathrm{m}^{-4}\right)\end{array}$} \\
& July 2003 & July 2004 & July 2003 & July 2004 \\
\hline South area & $12 \pm 0.45$ & $16 \pm 3.16$ & $0.60 \pm 0.07$ & $0.23 \pm 0.05$ \\
North area & $20 \pm 4.39$ & $30 \pm 13.54$ & $0.23 \pm 0.07$ & $0.37 \pm 0.20$ \\
\hline
\end{tabular}


July 2003
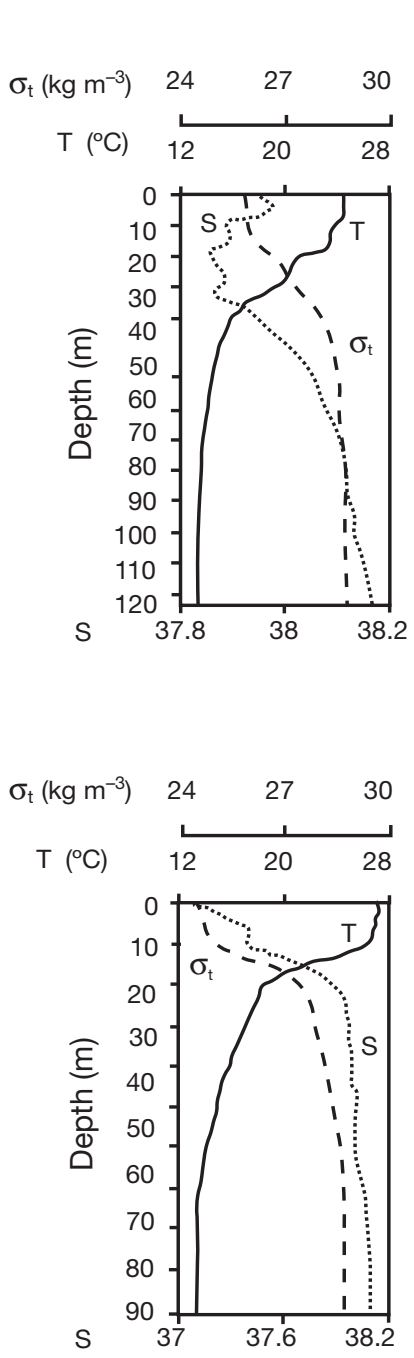

\section{North area}

No. of Nauplii $\mathrm{m}^{-3}$

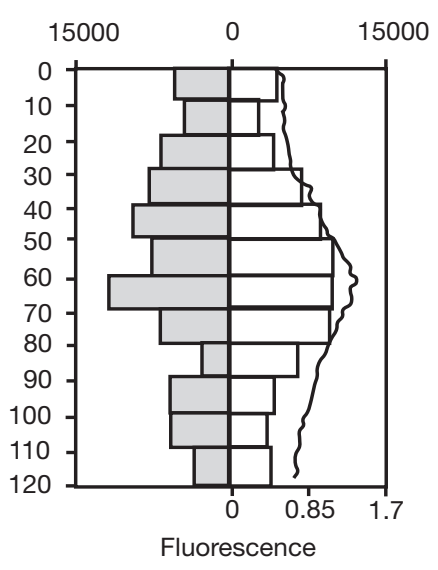

South area

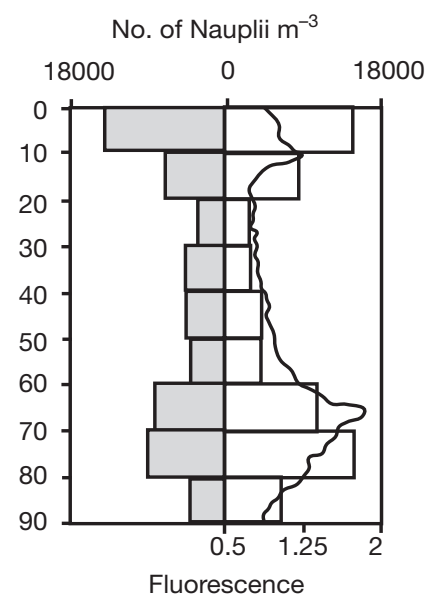

No. of Copepodites $\mathrm{m}^{-3}$

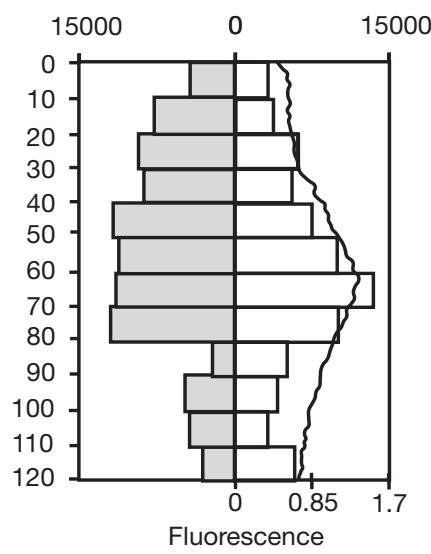

No. of Copepodites $\mathrm{m}^{-3}$

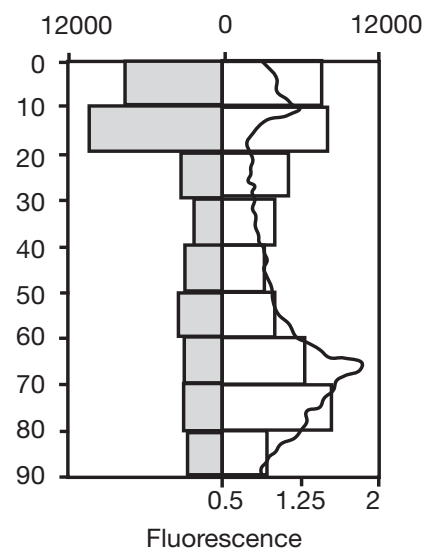

Fig. 3. Mean vertical profiles of temperature (T), salinity $(\mathrm{S})$ and density $\left(\sigma_{t}\right)$, and mean vertical distributions of fluorescence $(-)$ and nauplii and copepodite stages of copepods in daytime (white bars) and night-time (grey bars) for the south and north sampling areas in July 2003

between the southern and northern areas. The vertical distributions of both microzooplankton groups were well correlated with that of fluorescence at the same depth intervals (correlation significant at $\mathrm{p}<0.05 ; \mathrm{r}=0.47$ for nauplii and $r=0.40$ for copepodites). Accordingly, in the south, high concentrations were detected in the upper $20 \mathrm{~m}$, which were associated with the SCM (Figs. 3 \& 4), although it was not as evident for copepodites in July 2003. Another abundance peak was observed between 60 and $80 \mathrm{~m}$ depth, coinciding with the DCM. In the northern area, the highest concentrations were detected between 50 and $80 \mathrm{~m}$, at levels close to the DCM, which was located between 60 and $70 \mathrm{~m}$. In this area, no surface relative maximum was observed, in accordance with the absence of the SCM. Although the copepodites showed a certain tendency to be closer to the surface during the night, no indication of diel vertical migrations was evident for the nauplii (Figs. $3 \& 4$ ).

\section{Fish eggs and larvae}

The vertical distribution patterns of eggs and larvae of Sardinella aurita and Engraulis encrasicolus were very similar in the 2 sampling years. Complete data of abundances by size classes and depth stratum are shown in Table 2.

The vertical distribution of eggs (in July 2004), superimposed on density distributions, is presented in Fig. 5. The eggs of Sardinella aurita were close to the 

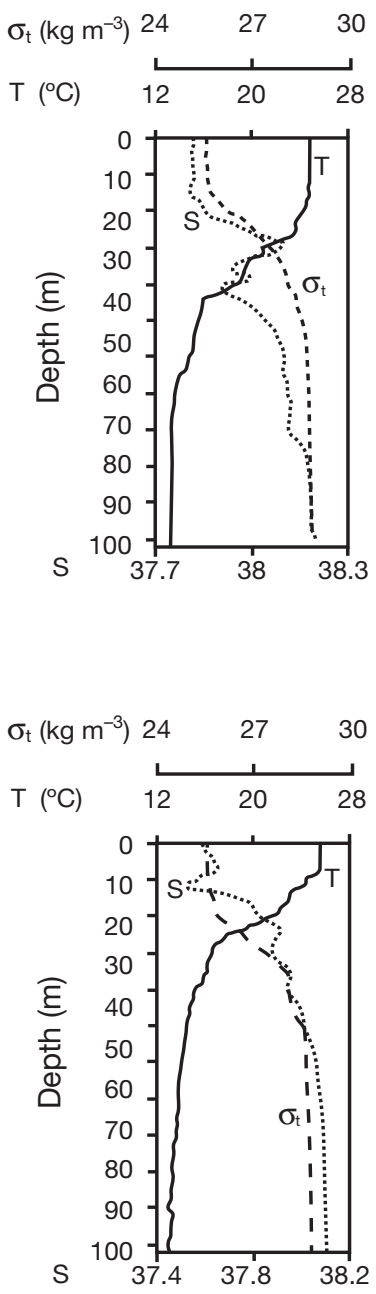

July 2004

North area

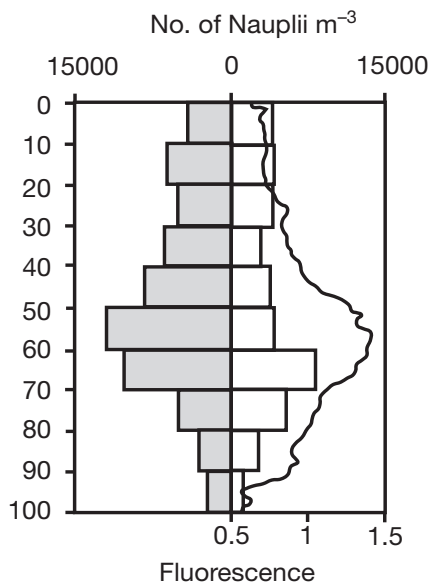

South area

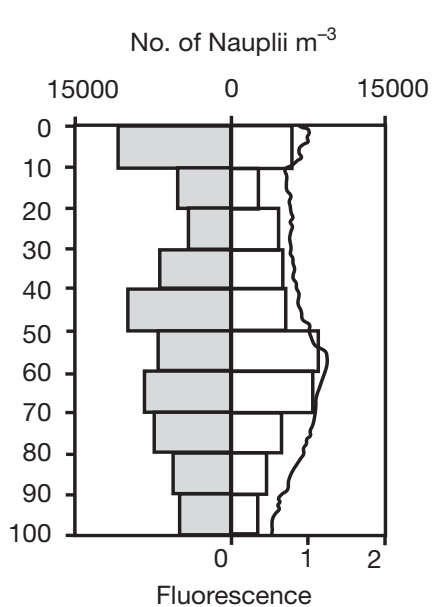

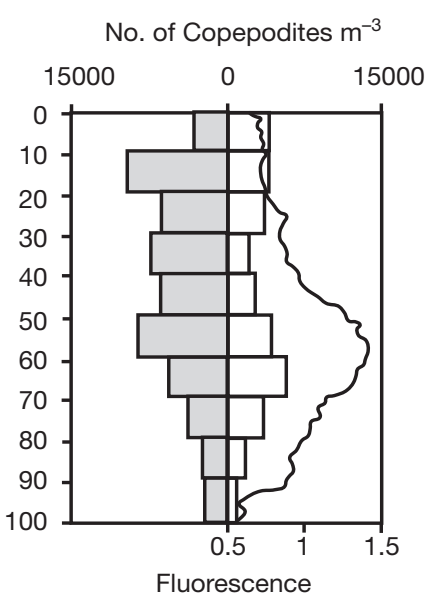

No. of Copepodites $\mathrm{m}^{-3}$

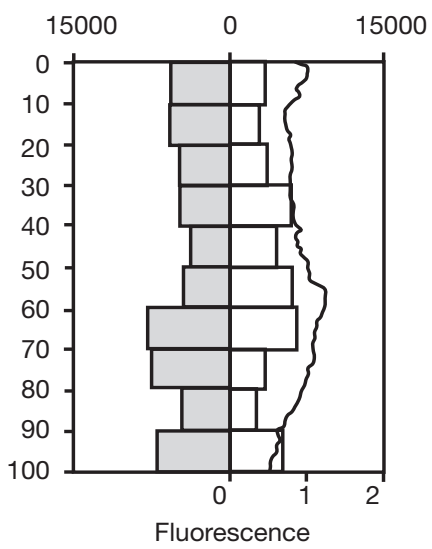

Fig. 4. Mean vertical profiles of temperature $(\mathrm{T})$, salinity $(\mathrm{S})$ and density $\left(\sigma_{t}\right)$, and mean vertical distributions of fluorescence $(-)$ and nauplii and copepodite stages of copepods in daytime (white bars) and night-time (grey bars) for the south and north sampling areas in July 2004

surface, mainly in the upper $10 \mathrm{~m}$, well above the pycnocline, both in the southern and in the northern areas (Fig. 5). This is also evident in the distribution of the centre of mass $\left(Z_{\mathrm{CM}}\right)$ versus pycnocline depth (Fig. 6, Table 3). The eggs of Engraulis encrasicolus showed a wider distribution, with the maximum abundances associated with the highest density gradient, around the depth of the base of the pycnocline (Fig. 5). The $Z_{\mathrm{CM}}$ for anchovy eggs extended down to nearly $30 \mathrm{~m}$ (Fig. 6, Table 3) and was well correlated with pycnocline depth $(r=0.61 ; \mathrm{p}<0.05)$.

The larval abundances, by size, at the different depth intervals are presented in Table 2 . We used the $Z_{\mathrm{CM}}$ at different developmental stages (Fig. 6, Table 3) to quantify vertical patterns of distribution. The results of ANOVAs performed to compare years, areas and day/night are presented in Table 4 . These results show that (1) there were no differences between years, (2) the differences between areas were only significant for anchovy $>6 \mathrm{~mm} \mathrm{SL}$, and (3) day/night differences were significant for both anchovy $>6 \mathrm{~mm}$ SL and round sardinella $>8 \mathrm{~mm}$ SL. In addition, these results show that the only significant interaction was time and area for anchovy larvae $>8 \mathrm{~mm} \mathrm{SL}$, since the $Z_{\mathrm{CM}}$ values during the day in the north area were deeper than those in the rest of the cases.

The variability found in the $Z_{\mathrm{CM}}$ distributions can be analysed in more detail from the vertical distributions of larvae by size groups and areas (Figs. 7 \& 8) in 2003. We used this year, with the highest abundances, because there were no significant differences between years in $Z_{\mathrm{CM}}$ distributions. During the night, larvae of 
Table 2. Sardinella aurita and Engraulis encrasicolus. Mean $( \pm \mathrm{SD})$ densities (no. $100 \mathrm{~m}^{-3}$ ) of eggs and larvae by size class (mm) at each depth stratum (all stations combined), for July 2003 and July 2004. N: night; D: day

\begin{tabular}{|c|c|c|c|c|c|c|c|c|c|c|}
\hline \multirow[t]{2}{*}{ Year } & \multirow[t]{2}{*}{ Depth (m) } & \multirow[t]{2}{*}{ Time } & \multicolumn{4}{|c|}{ S. aurita } & \multicolumn{4}{|c|}{-E. encrasicolus } \\
\hline & & & Eggs & $<6$ & $6-8$ & $>8$ & Eggs & $<6$ & $6-8$ & $>8$ \\
\hline \multirow[t]{24}{*}{2003} & $1-10$ & $\mathrm{~N}$ & $27 \pm 50$ & $57 \pm 100$ & $12 \pm 20$ & $11 \pm 13$ & $97 \pm 120$ & $71 \pm 66$ & $65 \pm 49$ & $20 \pm 21$ \\
\hline & & $\mathrm{D}$ & $62 \pm 117$ & $53 \pm 32$ & $23 \pm 22$ & $1 \pm 0$ & $66 \pm 80$ & $40 \pm 53$ & $3 \pm 3$ & $2 \pm 3$ \\
\hline & $11-20$ & $\mathrm{~N}$ & $6 \pm 11$ & $49 \pm 92$ & $5 \pm 7$ & $5 \pm 7$ & $43 \pm 53$ & $74 \pm 69$ & $56 \pm 48$ & $20 \pm 11$ \\
\hline & & $\mathrm{D}$ & $40 \pm 100$ & $84 \pm 71$ & $26 \pm 24$ & $5 \pm 6$ & $31 \pm 43$ & $37 \pm 46$ & $3 \pm 4$ & $2 \pm 2$ \\
\hline & $21-30$ & $\mathrm{~N}$ & - & $12 \pm 22$ & $1 \pm 3$ & $2 \pm 4$ & $3 \pm 3$ & $70 \pm 89$ & $46 \pm 40$ & $17 \pm 15$ \\
\hline & & $\mathrm{D}$ & $1 \pm 2$ & $17 \pm 13$ & $15 \pm 20$ & $4 \pm 5$ & $17 \pm 21$ & $37 \pm 41$ & $12 \pm 19$ & $3 \pm 4$ \\
\hline & $31-40$ & $\mathrm{~N}$ & - & $13 \pm 26$ & - & - & $2 \pm 3$ & $25 \pm 24$ & $27 \pm 38$ & $19 \pm 24$ \\
\hline & & $\mathrm{D}$ & - & $7 \pm 8$ & $9 \pm 8$ & $4 \pm 4$ & $4 \pm 7$ & $30 \pm 43$ & $15 \pm 22$ & $7 \pm 10$ \\
\hline & $41-50$ & $\mathrm{~N}$ & - & $7 \pm 14$ & - & - & $1 \pm 2$ & $21 \pm 32$ & $19 \pm 25$ & $6 \pm 9$ \\
\hline & & $\mathrm{D}$ & & $1 \pm 1$ & $1 \pm 2$ & $1 \pm 2$ & $2 \pm 3$ & $14 \pm 22$ & $16 \pm 28$ & $7 \pm 13$ \\
\hline & $51-60$ & $\mathrm{~N}$ & - & $2 \pm 3$ & - & - & - & $6 \pm 9$ & $5 \pm 10$ & - \\
\hline & & $\mathrm{D}$ & - & - & $0 \pm 1$ & - & $1 \pm 2$ & $2 \pm 4$ & $5 \pm 10$ & $4 \pm 9$ \\
\hline & $61-70$ & $\mathrm{~N}$ & - & - & - & - & $2 \pm 3$ & $1 \pm 1$ & $2 \pm 3$ & - \\
\hline & & $\mathrm{D}$ & - & - & - & - & $1 \pm 2$ & $1 \pm 2$ & $2 \pm 4$ & $4 \pm 6$ \\
\hline & $71-80$ & $\mathrm{~N}$ & - & - & - & - & $1 \pm 2$ & $2 \pm 3$ & - & - \\
\hline & & $\mathrm{D}$ & - & - & - & - & - & $1 \pm 2$ & $1 \pm 2$ & $3 \pm 4$ \\
\hline & $81-90$ & $\mathrm{~N}$ & - & - & - & - & - & - & - & - \\
\hline & & $\mathrm{D}$ & - & - & - & - & - & $2 \pm 3$ & $2 \pm 4$ & $3 \pm 5$ \\
\hline & $91-100$ & $\mathrm{~N}$ & - & - & - & - & - & - & - & - \\
\hline & & $\mathrm{D}$ & - & - & - & - & - & $2 \pm 2$ & - & $1 \pm 1$ \\
\hline & $101-110$ & $\mathrm{~N}$ & - & - & - & - & - & - & - & - \\
\hline & & D & - & - & - & - & - & - & $1 \pm 1$ & $1 \pm 1$ \\
\hline & $111-120$ & $\mathrm{~N}$ & - & - & - & - & & - & - & - \\
\hline & & D & - & - & - & - & & $2 \pm 2$ & $1 \pm 1$ & $3 \pm 5$ \\
\hline \multirow[t]{24}{*}{2004} & $1-10$ & $\mathrm{~N}$ & $2 \pm 82$ & $34 \pm 36$ & $33 \pm 43$ & $9 \pm 8$ & $265 \pm 239$ & $17 \pm 12$ & $30 \pm 32$ & $21 \pm 22$ \\
\hline & & $\mathrm{D}$ & $145 \pm 236$ & $25 \pm 22$ & $4 \pm 4$ & - & $209 \pm 230$ & $2 \pm 2$ & - & $1 \pm 1$ \\
\hline & $11-20$ & $\mathrm{~N}$ & - & $24 \pm 35$ & $24 \pm 44$ & $9 \pm 12$ & $332 \pm 265$ & $28 \pm 17$ & $29 \pm 35$ & $27 \pm 24$ \\
\hline & & $\mathrm{D}$ & $65 \pm 112$ & $100 \pm 132$ & $23 \pm 26$ & $3 \pm 3$ & $554 \pm 633$ & $12 \pm 10$ & $6 \pm 6$ & $3 \pm 4$ \\
\hline & $21-30$ & $\mathrm{~N}$ & - & $3 \pm 5$ & $5 \pm 6$ & $3 \pm 2$ & $370 \pm 532$ & $18 \pm 19$ & $13 \pm 14$ & $10 \pm 11$ \\
\hline & & $\mathrm{D}$ & $25 \pm 44$ & $14 \pm 12$ & $8 \pm 7$ & $3 \pm 6$ & $93 \pm 91$ & $7 \pm 7$ & $10 \pm 10$ & $4 \pm 4$ \\
\hline & $31-40$ & $\mathrm{~N}$ & - & - & $1 \pm 3$ & - & $95 \pm 107$ & $9 \pm 14$ & $6 \pm 8$ & $8 \pm 11$ \\
\hline & & $\mathrm{D}$ & $5 \pm 10$ & $14 \pm 28$ & $3 \pm 6$ & $1 \pm 1$ & $41 \pm 40$ & $3 \pm 3$ & $5 \pm 6$ & $4 \pm 5$ \\
\hline & $41-50$ & $\mathrm{~N}$ & - & $1 \pm 2$ & - & - & $30 \pm 35$ & $3 \pm 4$ & $1 \pm 3$ & $6 \pm 6$ \\
\hline & & $\mathrm{D}$ & $1 \pm 3$ & $11 \pm 19$ & - & - & $21 \pm 25$ & $3 \pm 4$ & $2 \pm 4$ & $8 \pm 17$ \\
\hline & $51-60$ & $\mathrm{~N}$ & - & - & - & - & $7 \pm 7$ & - & $1 \pm 1$ & $1 \pm 1$ \\
\hline & & $\mathrm{D}$ & - & $1 \pm 2$ & - & - & $10 \pm 7$ & $1 \pm 1$ & $1 \pm 2$ & $28 \pm 54$ \\
\hline & $61-70$ & $\mathrm{~N}$ & - & - & $1 \pm 2$ & - & $6 \pm 8$ & - & - & - \\
\hline & & $\mathrm{D}$ & - & $2 \pm 4$ & - & $1 \pm 1$ & $5 \pm 3$ & $1 \pm 1$ & - & $15 \pm 28$ \\
\hline & $71-80$ & $\mathrm{~N}$ & - & - & - & - & - & - & - & - \\
\hline & & $\mathrm{D}$ & - & - & $1 \pm 2$ & - & $4 \pm 3$ & - & $1 \pm 2$ & $1 \pm 2$ \\
\hline & $81-90$ & $\mathrm{~N}$ & - & - & - & - & $6 \pm 6$ & - & - & - \\
\hline & & $\mathrm{D}$ & - & - & - & - & $11 \pm 8$ & - & - & - \\
\hline & $91-100$ & $\mathrm{~N}$ & - & - & - & - & $10 \pm 10$ & - & - & - \\
\hline & & $\mathrm{D}$ & - & - & - & - & $7 \pm 3$ & - & - & $2 \pm 2$ \\
\hline & $101-110$ & $\mathrm{~N}$ & - & - & - & - & - & - & - & - \\
\hline & & $\mathrm{D}$ & - & - & - & - & - & - & - & - \\
\hline & $111-120$ & $\mathrm{~N}$ & - & - & - & - & - & - & - & - \\
\hline & & $\mathrm{D}$ & - & - & - & - & - & - & - & - \\
\hline
\end{tabular}

all size classes of both species were located in the upper layers (mainly in the first $30 \mathrm{~m}$ ). The corresponding $Z_{\mathrm{CM}}$ were clearly above the pycnocline (Fig. 6). During the day, at the initial developmental stages (<6 mm SL), larvae of both species were largely found in the upper layers of the water column, between the surface and $20 \mathrm{~m}$. Their $Z_{\mathrm{CM}}$ was situated above or close to the pycnocline (Fig. 6). As they grew their distribution became wider, although it did not extend beyond $50 \mathrm{~m}$ depth in the south (Fig. 8). In the northern area, the patterns of vertical distribution of larger larvae showed differences between species. Larvae of Sardinella aurita from $8 \mathrm{~mm}$ SL onwards were mainly found between 20 and $40 \mathrm{~m}$, but never deeper than $50 \mathrm{~m}$ (Fig. 7). Their $Z_{\mathrm{CM}}$ was generally located below the pycnocline, although never below $40 \mathrm{~m}$ depth (Fig. 6, Table 3). The maximum abundances of anchovy larvae (6 to $8 \mathrm{~mm}$ SL) appeared between 


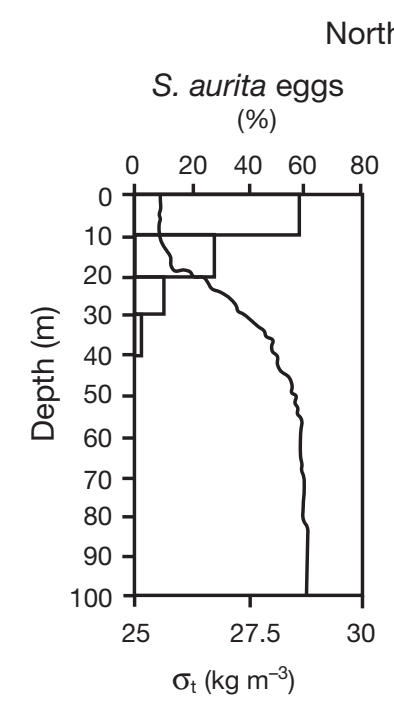

North area
E. encrasicolus eggs

(\%)

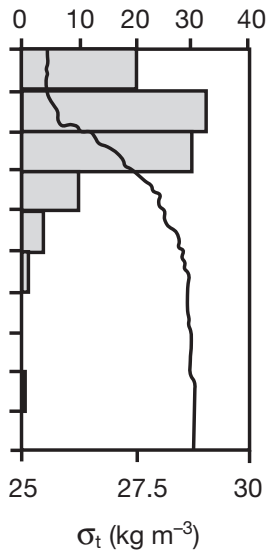

South area

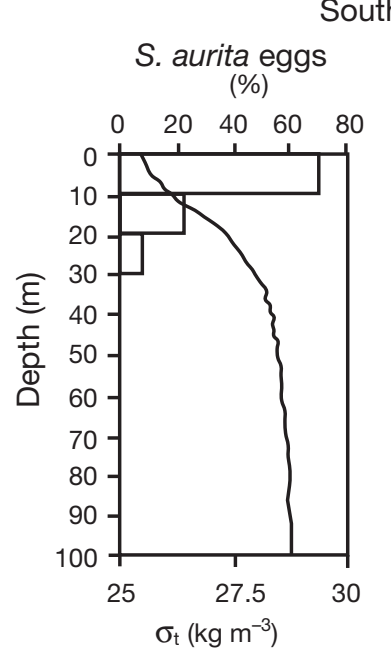

E. encrasicolus eggs (\%)

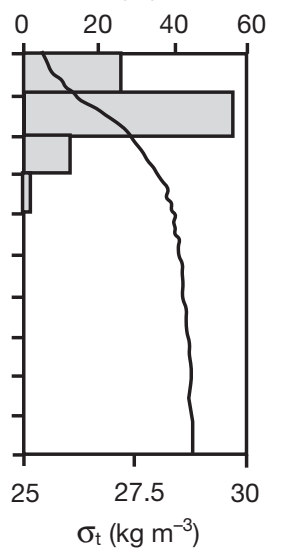

Fig. 5. Sardinella aurita and Engraulis encrasicolus. Mean vertical distribution of eggs and density $\left(\sigma_{t}\right)$, for the south and north sampling areas, in July 2004. The percentages calculated are based on the mean abundance at all stations for each depth stratum

Table 3. Sardinella aurita and Engraulis encrasicolus. Daytime mean $( \pm \mathrm{SD})$ depth $\left(Z_{\mathrm{CM}}\right)$ of eggs and larvae by size class, areas and years

\begin{tabular}{|c|c|c|c|c|}
\hline & \multicolumn{4}{|c|}{$Z_{\mathrm{CM}}(\mathrm{m})$} \\
\hline & \multicolumn{2}{|c|}{ South } & \multicolumn{2}{|c|}{ North } \\
\hline & July 2003 & July 2004 & July 2003 & July 2004 \\
\hline S. aurita eggs & $7 \pm 5.0$ & $6 \pm 1.3$ & $6 \pm 2.1$ & $5 \pm 3.9$ \\
\hline S. aurita $<6 \mathrm{~mm}$ & $16 \pm 1.3$ & $12 \pm 3.5$ & $14 \pm 2.8$ & $18 \pm 3.5$ \\
\hline S. aurita $6-8 \mathrm{~mm}$ & $16 \pm 6.4$ & $9 \pm 6.2$ & $17 \pm 2.8$ & $15 \pm 1.5$ \\
\hline S. aurita $>8 \mathrm{~mm}$ & $27 \pm 12.3$ & $18 \pm 5.2$ & $24 \pm 5.0$ & $27 \pm 12.3$ \\
\hline E. encrasicolus eggs & $11 \pm 3.4$ & $17 \pm 7.3$ & $16 \pm 1.3$ & $20 \pm 10.1$ \\
\hline E. encrasicolus $<6 \mathrm{~mm}$ & $14 \pm 2.1$ & $18 \pm 0.2$ & $23 \pm 10.4$ & $21 \pm 2.0$ \\
\hline E. encrasicolus $6-8 \mathrm{~mm}$ & $24 \pm 2.2$ & $21 \pm 0.8$ & $31 \pm 8.6$ & $34 \pm 1.4$ \\
\hline E. encrasicolus > $>8 \mathrm{~mm}$ & $16 \pm 0.5$ & $20 \pm 4.0$ & $46 \pm 15.0$ & $59 \pm 6.6$ \\
\hline
\end{tabular}

20 and $50 \mathrm{~m}$, and from $8 \mathrm{~mm}$ SL onwards they showed a much more extended distribution, between 30 and $90 \mathrm{~m}$ (Fig. 7). $Z_{\mathrm{CM}}$ for Engraulis encrasicolus was deeper than that of $S$. aurita with a day/night migratory behaviour evident in larvae $>6 \mathrm{~mm}$ SL (Fig. 6, Table 3). From this size, the $Z_{\mathrm{CM}}$ was below the pycnocline, reaching $70 \mathrm{~m}$ in larvae $>8 \mathrm{~mm}$ SL.

\section{DISCUSSION}

The environmental conditions found in both years were in general those expected for the season, though the surface temperature in summer 2003 was around $2{ }^{\circ} \mathrm{C}$ higher than usual in the whole region. This could be explained by the successive heat waves, reported at the time as extremely hot, that affected south-western Europe during the spring and summer of 2003 (Schär \& Jendritzky 2004). Consequently, the thermoclines in 2003 were shallower than in 2004. The maximum density gradient was found in the southern area in 2003. The presence of lower surface salinity near the Ebro River and the high temperatures in 2003 might have contributed to the enhancement of this pycnocline (Table 1).

The vertical distribution of nauplii and copepodites showed good agreement with the areas of high phytoplankton concentration, i.e. below the thermocline at the level of the DCM and close to the surface in the southern area affected by the Ebro River runoff. Development of a DCM during the stratified period is a wellknown feature in the area (Estrada 1985). DCM phytoplankton cells are preyed on by herbivorous zooplankton (Saiz \& Alcaraz 1990), and high zooplankton biomass has been found associated with the DCM during daylight hours (Alcaraz 1985).

The vertical distribution of pelagic eggs, according to Sundby (1991), is determined by a set of interacting biological and physical processes, namely the properties of the eggs (density, diameter) and the ambient sea water (density, viscosity, turbulence). Generally, pelagic fish eggs have a specific density which is lower than that of the upper mixed layer of the sea, and they tend to rise towards the surface (Sundby 1991). In the present study, the eggs of both species were located in relatively superficial waters. Nevertheless, although the eggs of Sardinella aurita were clearly located above the pycnocline, the Engraulis encrasicolus eggs showed a certain tendency to accumulate at the base of the pycnocline. This suggests that the density of the anchovy eggs is higher than that of $S$. aurita eggs. While eggs of the latter 

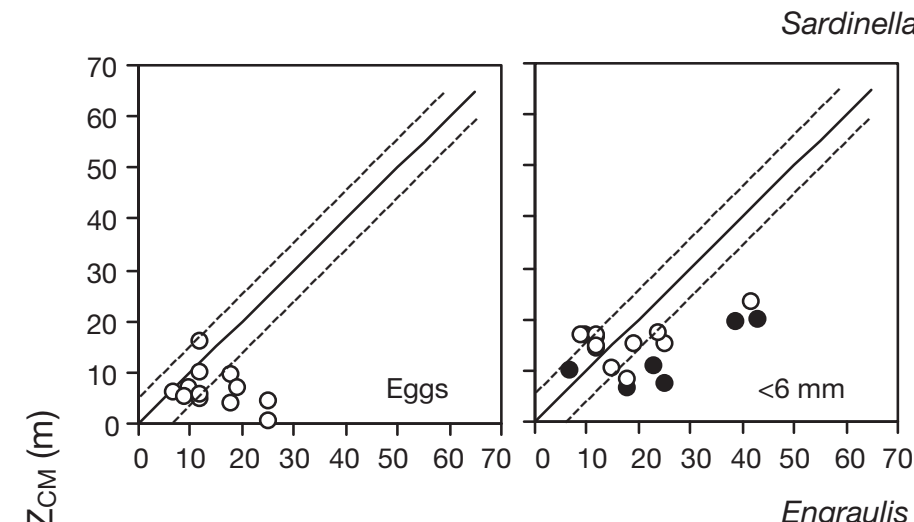

Sardinella aurita
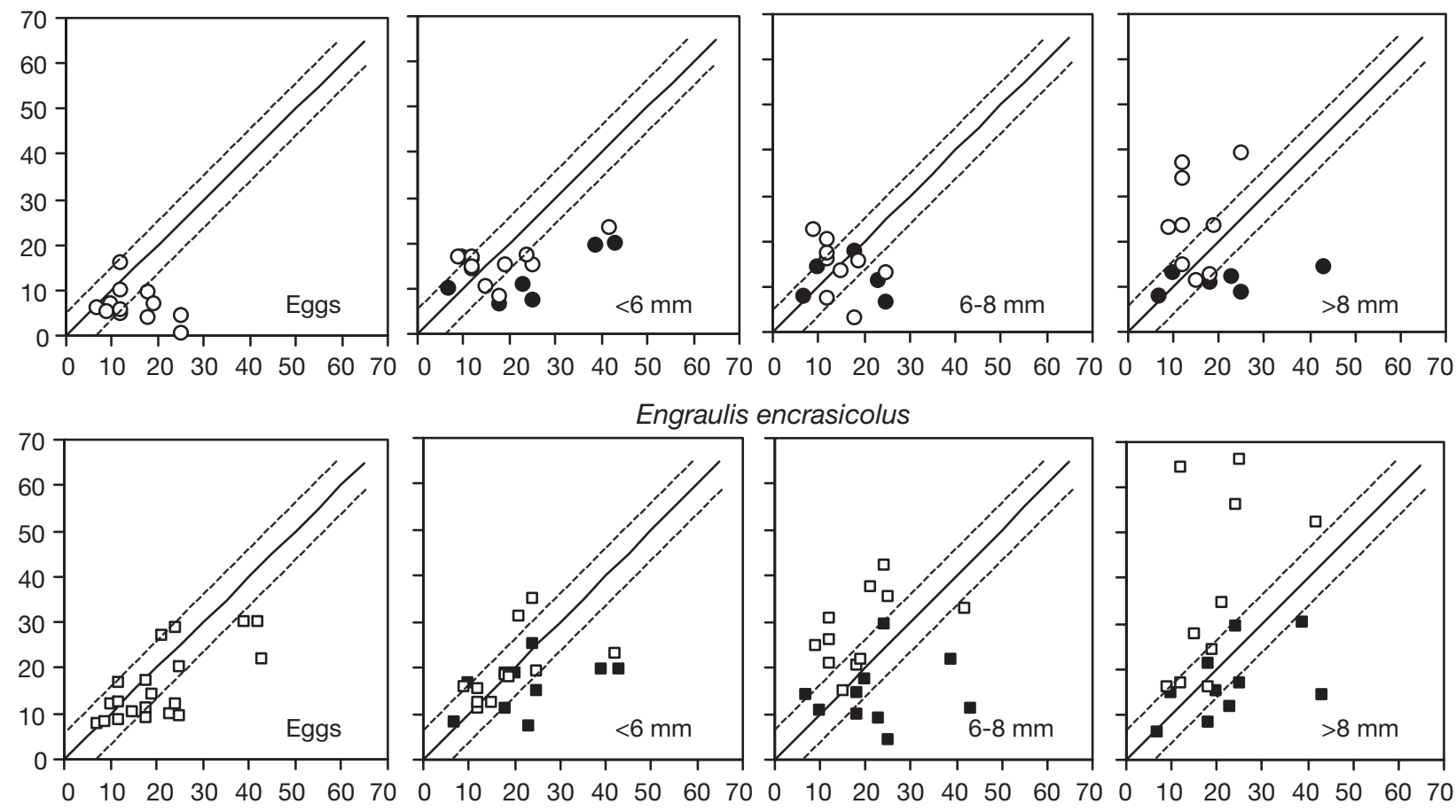

Engraulis encrasicolus

Pycnocline depth $(\mathrm{m})$

Fig. 6. Sardinella aurita and Engraulis encrasicolus. Relationships between the depth of the pycnocline and mean depth $\left(Z_{\mathrm{CM}}\right)$ of eggs and larvae by size class for day (open symbols) and night (filled symbols) (samples 2003 and 2004 combined). The slope line is included to better represent the depth of the pycnocline. Dashed lines are drawn at $\pm 5 \mathrm{~m}$

species are clearly less dense than the surface waters, those of the anchovy have a similar or slightly higher density than the upper mixed layer, on the order of 1026.5 to $1027 \mathrm{~kg} \mathrm{~m}^{-3}$, which would make them accumulate in the pycnocline. The observed lower density of eggs of $S$. aurita would allow them to develop at slightly higher temperatures than those of the anchovy, in more favourable conditions for a species characteristically from warm waters. Although no references have been found concerning the vertical distribution of S. aurita eggs, the concentration of anchovy eggs in the pycnocline has been reported by Motos \& Coombs (2000) and Coombs et al. (2004) in the Cantabrian Sea (south of the Gulf of Biscay) at similar densities to those detected in the present work. Olivar et al. (2001), in a study carried out in the NW Mediterranean, indicated that anchovy eggs were largely found in the upper $10 \mathrm{~m}$, clearly above the pycnocline. Nevertheless, the density corresponding to the upper mixed layer observed in this latter work was $1027 \mathrm{~kg} \mathrm{~m}^{-3}$, higher than that found in the present study.
Consequently, the anchovy eggs probably have a density on this order independent of the environmental density. This observation did not match the results of Petitgas et al. (2006), who modelled the vertical distribution of eggs of pelagic species. These authors indicated that the density values of different species (sardine, sprat and anchovy) varied in coherence with each other, meaning that across species there was a similar process of egg density adaptation.

The larvae of both species showed diel vertical movements as larval development progressed. The vertical displacements showed differences between the 2 areas studied, but the patterns observed for each

Table 4. Three-way ANOVA testing for differences in $Z_{\mathrm{CM}}$ for each larval size class by year (2003/2004), area (north/south) and time (day/night). The interaction listed is the only one that has some significance. NS: not significant

\begin{tabular}{|lccccccc|}
\hline & \multicolumn{3}{c}{ Sardinella aurita } & \multicolumn{3}{c|}{ Engraulis encrasicolus } \\
& $<6 \mathrm{~mm}$ & $6-8 \mathrm{~mm}$ & $>8 \mathrm{~mm}$ & $<6 \mathrm{~mm}$ & $6-8 \mathrm{~mm}$ & $>8 \mathrm{~mm}$ \\
\hline Time: day/night & \multirow{2}{*}{ NS } & NS & $\mathrm{p}<0.022$ & $\mathrm{NS}$ & $\mathrm{p}<0.015$ & $\mathrm{p}<0.001$ \\
Area: north/south & $\mathrm{NS}$ & $\mathrm{NS}$ & $\mathrm{NS}$ & $\mathrm{NS}$ & $\mathrm{p}<0.008$ & $\mathrm{p}<0.001$ \\
Year: $2003 / 2004$ & $\mathrm{NS}$ & $\mathrm{NS}$ & $\mathrm{NS}$ & $\mathrm{NS}$ & $\mathrm{NS}$ & $\mathrm{NS}$ \\
Time $\times$ Area & NS & NS & NS & NS & $\mathrm{NS}$ & $\mathrm{p}<0.015$ \\
\hline
\end{tabular}


species were the same in the 2 studied years. During the night, the larvae of both species were located in the most superficial layers, above the pycnocline, independent of their size. This has already been documented in the larvae of Engraulis encrasicolus as well as in other clupeoid species (Neilson \& Perry 1990, Olivar et al. 2001), but was not known in the case of Sardinella aurita. It is assumed that, in general, clupeoid larvae migrate upwards at night to fill their gas bladders at the sea surface to reduce the energetic cost of swimming during the night, when the larvae do not feed (Hunter \& Sánchez 1976). During daylight hours, i.e. the feeding period (Conway et al. 1998), larvae of both species $>6 \mathrm{~mm}$ SL were located in deeper levels of the water column. Clear evidence of diel vertical migration was especially apparent in anchovy larvae $>6 \mathrm{~mm}$ SL. This size corresponds with the development of the

North area

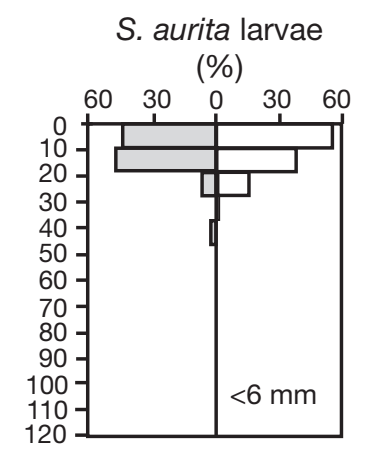

\section{E. encrasicolus larvae} (\%)
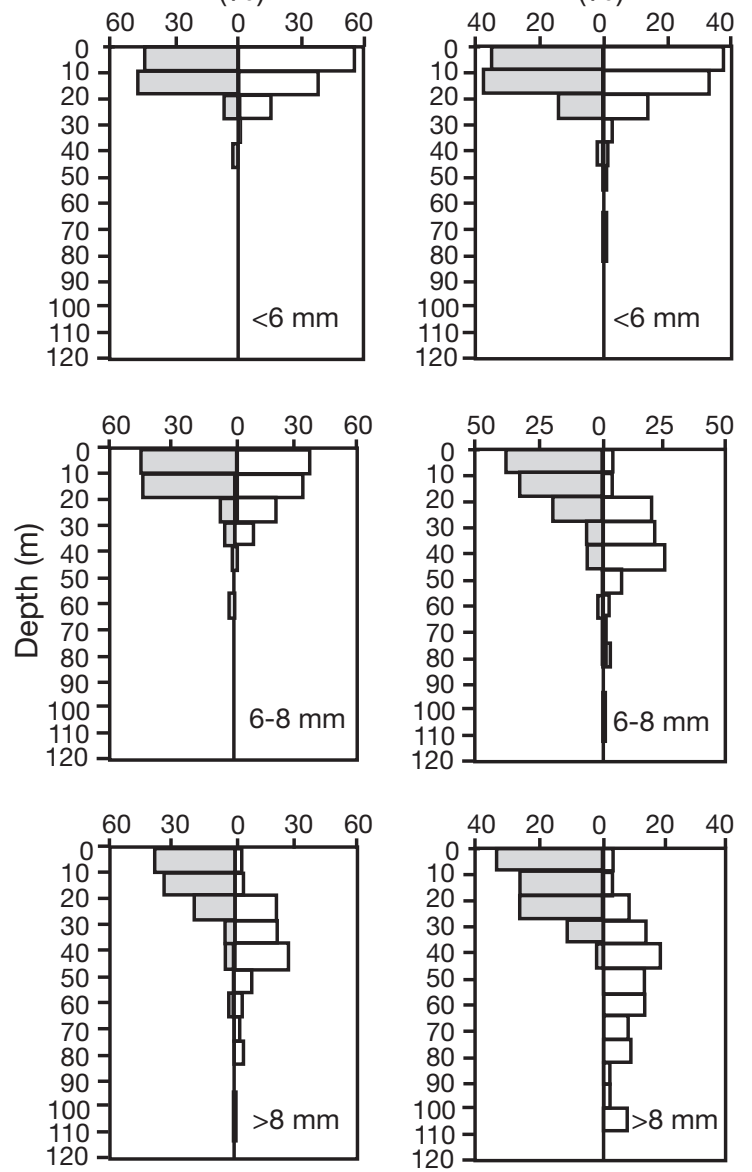

Fig. 7. Sardinella aurita and Engraulis encrasicolus. Vertical distribution of larvae by size class in daytime (white bars) and night-time (grey bars) for the north area in July 2003. The percentages calculated are based on the mean abundance at all stations for each depth stratum caudal fin and coincides with behavioural changes, as the onset of vertical migrations (Somarakis \& Nikolioudakis 2007). These displacements, however, were much more evident in the northern than in the southern area. If we consider the effort required to cross strong density gradients such as those present in summer, we can argue that the vertical movements might be limited above a certain threshold value of the vertical density gradient. Some studies effectively indicate that strong pycnoclines can act as a physical barrier for the diel vertical migration of fish larvae (Davis et al. 1990). Moreover, the greatest concentrations of fish larvae in stratified water columns have been found in and above the thermocline (Ahlstrom 1959, Kendall \& Naplin 1981). In the present study, according to the values recorded in the different situations (Table 1), the 2004 gradient in the north was greater than that in

South area

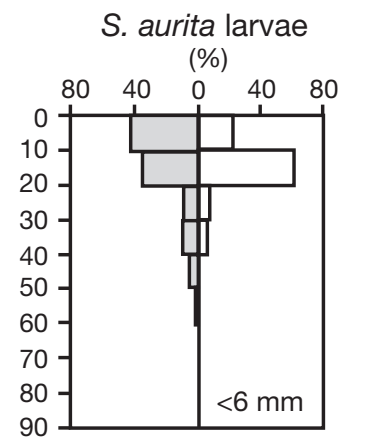

E. encrasicolus larvae
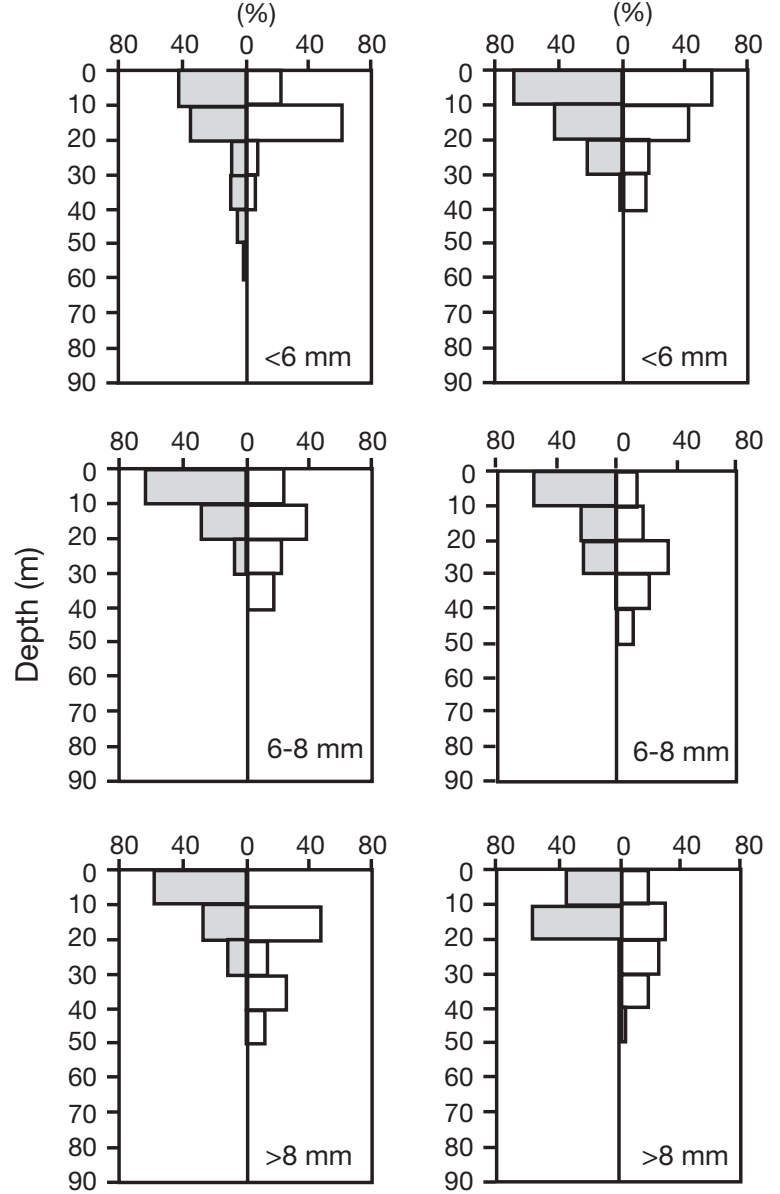

Fig. 8. Sardinella aurita and Engraulis encrasicolus. Vertical distribution of larvae by size class in daytime (white bars) and night-time (grey bars) for the south area in July 2003. The percentages calculated are based on the mean abundance at all stations for each depth stratum 
the south, whereas, in 2003, an opposite trend was observed. Therefore, if fish larvae could cross the pycnocline in the north in 2004 (Table 3), there should be no problem to do so in the south, at least in this same year. Hence, the effort to cross the pycnocline would not be a limiting factor for vertical displacement.

The diel vertical migrations depend on a combination of factors, such as thermal structure, availability of prey and light (Kendall \& Naplin 1981, Munk et al. 1989, Olla \& Davis 1990). Fish larvae may accumulate where prey are concentrated, either by modifying their behaviour when they find good foraging conditions (Munk \& Kiorboe 1985) or in association with physical conditions, such as the thermocline, where prey aggregate (Munk et al. 1989). We could suggest that, in the present study, the differences found in the vertical distribution of larvae between areas could respond to the vertical distribution of their prey. In the southern area, where a SCM was well developed under the influence of Ebro River runoff, the abundance of nauplii and copepodite stages of copepods at the surface was higher than in the northern area at the same levels, and similar to that found at the DCM level, below the pycnocline. Then, the fact that, in the southern area, the larvae of both species were found in relatively superficial layers, independent of their developmental stage, could correspond to the relative abundance of food at these upper levels. We could thus argue that the vertical displacements to feed were not necessary in the southern area. However, in the north, in the absence of surface fertilization mechanisms, the primary production was limited to the DCM, and, accordingly, the highest concentrations of nauplii and copepodites were always found below the pycnocline. In this situation, while the advanced developmental stages of anchovy larvae were found at considerable depths, near the DCM, coinciding with the high abundance of prey, Sardinella aurita larvae never reached depths $>50 \mathrm{~m}$. This migratory behaviour of anchovy larvae has already been described by Olivar et al. (2001) in a similar stratification situation, and it was justified by the food aggregation at the DCM level.

Why do Sardinella aurita larvae not behave similarly? Is there any physical factor that might hinder the vertical migration of $S$. aurita towards deeper levels? Physical factors that can affect the depth distribution of fish larvae are light, turbulence and temperature (Heath et al. 1988, Munk et al. 1989, Olla \& Davis 1990). Among these factors, and considering the thermophilic character of $S$. aurita (Ben Tuvia 1960), we suggest temperature could be a limiting factor, since at the levels corresponding to the DCM the temperature $\left(\sim 15^{\circ} \mathrm{C}\right)$ could be too low. Fish larvae, as poikilothermic organisms, show a preference for certain temperature ranges that are generally associated with physiological and growth optima (Blaxter 1992). It has been reported that fish larvae are capable of adjusting their depth distribution in order to avoid unfavourable temperatures (Olla \& Davis 1990). Therefore, we should explore whether the temperature detected at the DCM is unfavourable for the larvae of $S$. aurita, even though this is where the maximum food abundances are located. It should be pointed out that $S$. aurita is a very abundant species in upwelling regions of the central Atlantic. In these areas, it reproduces when the temperatures reach the local annual maximum (Ettahiri et al. 2003). Compared with conditions in the Mediterranean in summer, in upwelling regions maximum surface temperature is lower $\left(18\right.$ to $\left.21^{\circ} \mathrm{C}\right)$, vertical stratification is weaker and the surface layers are richer in food for the larvae. In the present study, in the northern area, high food concentrations were only found at the DCM level, below the pycnocline, where temperature is lower than in the upwelling regions.

Whatever the reason, the results of the present study show that the larvae of Sardinella aurita have difficulties reaching depths below $50 \mathrm{~m}$. This is a weakness for obtaining food in the zones where surface primary production is limited. This behaviour puts $S$. aurita (in a phase of expansion) at a disadvantage in relation to the anchovy in the areas where larvae of both species coexist. This difficulty, in addition, could control the northward extension of $S$. aurita in the western Mediterranean. Conversely, the presence of productive surface waters on the Ebro shelf could have facilitated the expansion of this species along the southern half of the Catalan coast.

Acknowledgements. We greatly appreciate the assistance of the crew of the RV 'García del Cid' and all the participants during the 'CACO' cruises. We thank 3 anonymous reviewers for their accurate and constructive criticisms on an earlier version of the manuscript. This work was supported by the project REN 2002-01339/MAR.

\section{LITERATURE CITED}

Ahlstrom EH (1959) Vertical distribution of pelagic fish eggs and larvae off California and Baja California. Fish Bull (Wash DC) 60:107-146

Alcaraz M (1985) Vertical distribution of zooplankton biomass during summer stratification in the western Mediterranean. In: Gibbs PE (ed) 19th EMBS proceedings. Cambridge University Press, Cambridge, p 135-143

Astraldi M, Bianchi CN, Gasparini GP, Morri C (1995) Climatic fluctuations, current variability and marine species distribution: a case study in the Ligurian Sea (north-west Mediterranean). Oceanol Acta 18:139-149

Ben-Tuvia A (1960) Synopsis of biological data on Sardinella aurita of the Mediterranean Sea and other waters. FAO Fish Biol Synp 14:287-312

Bethoux JP, Gentili B (1996) The Mediterranean Sea, coastal and deep-sea signatures of climatic and environmental changes. J Mar Syst 7:383-394 
Bianchi CN, Morri C (2000) Marine biodiversity of the Mediterranean Sea: situation, problems and prospects for future research. Mar Pollut Bull 40:367-376

Blanc F, Leveau M, Szekielda KH (1969) Effets eutrophiques au débouché d'un grand fleuve (Grand Rhône). Mar Biol 3:233-242

Blaxter JHS (1986) Development of sense organs and behaviour of teleost larvae with special reference to feeding and predator avoidance. Trans Am Fish Soc 115:98-114

Blaxter JHS (1992) The effect of temperature on larval fishes. Neth J Zool 42:336-357

> Conway DVP, Coombs SH, Smith C (1998) Feeding of anchovy Engraulis encrasicolus larvae in the northwestern Adriatic Sea in response to changing hydrobiological conditions. Mar Ecol Prog Ser 175:35-49

> Coombs SH, Giovanardi O, Halliday NC, Franceschini G and others (2003) Wind mixing, food availability and mortality of anchovy larvae Engraulis encrasicolus in the northern Adriatic Sea. Mar Ecol Prog Ser 248:221-235

> Coombs SH, Boyra G, Rueda LD, Uriarte A, Santos M, Conway DVP, Halliday NC (2004) Buoyancy measurements and vertical distribution of eggs of sardine (Sardina pilchardus) and anchovy (Engraulis encrasicolus). Mar Biol 145:959-970

Davis TLO, Jenkins GP, Young JW (1990) Diel patterns of vertical distribution in larvae of southern bluefin Thunnus maccoyii, and other tuna in the East Indian Ocean. Mar Ecol Prog Ser 59:63-74

Estrada M (1985) Deep phytoplankton and chlorophyll maxima in the western Mediterranean. In: Moraitou-Apostolopoulou M, Kortsis V (eds) Mediterranean marine ecosystems. Plenum Press, New York, p 247-277

Estrada M, Marrasé C, Latasa M, Berdalet E, Delgado M, Riera T (1993) Variability of deep chorophyll maximum characteristics in the Northwestern Mediterranean. Mar Ecol Prog Ser 92:289-300

Ettahiri O, Berraho Am, Vidy G, Ramdani M, Do chi T (2003) Observation on the spawning of Sardina and Sardinella off south Moroccan Atlantic coast $\left(21-26^{\circ} \mathrm{N}\right)$. Fish Res 60:207-222

Francour P, Boudouresque CF, Harmelin JG, HarmelinVivien ML, Quignard JP (1994) Are the Mediterranean waters becoming warmer? Information from biological indicators. Mar Pollut Bull 28:523-526

Heath MR, Henderson EW, Baird DL (1988) Vertical distribution of herring larvae in relation to physical mixing and illumination. Mar Ecol Prog Ser 47:211-228

Hunter JR, Sánchez C (1976) Diel changes in swim bladder inflation of the larvae of the northern anchovy, Engraulis mordax. Fish Bull (Wash DC) 74:847-855

Kendall AW, Naplin NA (1981) Diel depth distribution of summer ichthyoplankton in the Middle Atlantic Bight. Fish Bull (Wash DC) 79:705-726

Lleonart J, Maynou F (2003) Fish stock assessments in the Mediterranean: state of the art. Sci Mar 67(Suppl):37-49

Motos L, Coombs S (2000) Vertical distribution of anchovy eggs and field observations of incubation temperature. Ozeanografika 3:253-272. See, http://aquariumss.com/en/ vidamarina/divulgacion/div_publicaciones.htm

Munk P, Kiorboe T (1985) Feeding behaviour and swimming activity of larval herring (Clupea harengus) in relation to density of copepod nauplii. Mar Ecol Prog Ser 24:15-21

Munk P, Kioerboe T, Christensen V (1989) Vertical migrations of herring, Clupea harengus, larvae in relation to light and prey distribution. Environ Biol Fishes 26:87-96

Neilson JD, Perry RI (1990) Diel vertical migrations of marine fishes: An obligate or facultative process? Adv Mar Biol 26:115-168

Olivar MP, Sabatés A (1997) Vertical distribution of fish larvae in the north-west Mediterranean Sea in spring. Mar Biol 129:289-300

Olivar MP, Salat J, Palomera I (2001) A comparative study of spatial distribution patterns of the early stages of anchovy and pilchard in the NW Mediterranean Sea. Mar Ecol Prog Ser 217:111-120

Oliver M, Navarro F (1952) La alacha y la sardina de Baleares. Investigaciones en 1950 y 1951. Bol Inst Esp Oceanogr 58:1-49

> Olla BL, Davis MW (1990) Effects of physical factors on the vertical distribution of larval walleye pollock Theragra chalcogramma under controlled laboratory conditions. Mar Ecol Prog Ser 63:105-112

Palomera I (1991) Vertical distribution of eggs and larvae of Engraulis encrasicolus in stratified waters of the western Mediterranean. Mar Biol 111:37-44

Palomera I, Sabatés A (1990) Co-occurrence of Engraulis encrasicolus and Sardinella aurita eggs and larvae in the western Mediterranean. Sci Mar 54:51-67

> Petitgas P, Magri S, Lazure P (2006) One-dimensional biophysical modelling of fish egg vertical distributions in shelf seas. Fish Oceanogr 15:413-428

Rohling EJ, Bryden H (1992) Man induced salinity and temperature increases in Mediterranean deep water. J Geophys Res 97:11191-11198

Sabatés A, Bozzano A, Vallvey I (2003) Feeding pattern and the visual light environment in myctophid fish larvae. J Fish Biol 63:1476-1490

Sabatés A, Martín P, Lloret J, Raya V (2006) Sea warming and fish distribution: the case of the small pelagic fish, Sardinella aurita, in the western Mediterranean. Glob Change Biol 12:2209-2219

Saiz E, Alcaraz M (1990) Pigment gut contents of copepods and deep phytoplankton maximum in the western Mediterranean. J Plankton Res 12:665-672

Salat J, Pascual J (2002) The oceanographic and meteorological station at l'Estartit (NW Mediterranean). Tracking long-term hydrological change in the Mediterranean Sea. CIESM Workshop Series 16:29-32. See, http:// www.ciesm.org/online/monographs/Monaco02.html

Salat J, García MA, Cruzado A, Palanques A and others (2002) Seasonal changes of water mass structure and shelf-slope exchanges at the Ebro Shelf (NW Mediterranean). Cont Shelf Res 22:327-348

Schär C, Jendritzky G (2004) Hot news from summer 2003. Nature 432:559-560

Somarakis S, Nikolioudakis N (2007) Oceanographic habitat, growth and mortality of larval anchovy (Engraulis encrasicolus) in the northern Aegean Sea (eastern Mediterranean). Mar Biol 152:1143-1158

Somarakis S, Drakopoulos P, Filippou V (2002) Distribution and abundance of larval fish in the northern Aegean Sea - eastern Mediterranean - in relation to early summer oceanographic conditions. J Plankton Res 24:339-357

Sundby S (1991) Factors affecting the vertical distribution of eggs. ICES Mar Sci Symp 192:33-38

Williams R, Collins NR, Conway DVP (1983) The double LHPR system, a high speed micro- and macroplankton sampler. Deep-Sea Res 30:331-342

Submitted: July 26, 2007; Accepted: February 25, 2008

Proofs received from author(s): July 7, 2008 